\title{
What kind of public spaces do we want?
}

\author{
E. Creanga, I. Budisteanu \& M. Duda \\ University Spiru Haret, Faculty of Architecture, Bucharest, Romania
}

\begin{abstract}
Public spaces within the city in all their different types and form - streets, boulevards, squares, plazas, market places, green areas - are the backbone of cities. Over the centuries buildings defined the shape and quality of public spaces, valorising them in various ways. The post-modern development of urban form generated a great number of "public spaces", where there is no longer correspondence between architectural forms and social and political messages: shopping malls and theme parks, inner public spaces, strip developments etc. To strike the right balance between inner city regeneration and under-use of urban land in the old abandoned areas are among of the main challenges confronting cities in Europe. The paper will analyze the complex relationships between architecture and public space, in an attempt to understand how traditional urban structures, public and green spaces, squares and streets, could provide orientation for quality-oriented regeneration. Case in point is Bucharest - capital city of Romania - where aggressive intervention in the urban structure during the 1980s disrupted the fabric of the city. The investigation is oriented towards fundamental questions such as: how to secure and preserve sites that would serve as initial points in upgrading processes, how to balance private investment criteria and the quality interests of the urban communities. The major aim is to provide a support for decision making in restoring the fundamental role of public urban space in shaping urban form and supporting community life. Keywords: public space, urban structure, regeneration, urban policy.
\end{abstract}

\section{Introduction}

Public spaces within the city are the backbone of urban structures. They are " $a$ measure of our ability to live with each other" [1]. Over the centuries cities provided public places that "would promote social encounters and serve the conduct of public affairs" [2]. From times medieval the little square in front of 
the cathedral and the main street were centres of community life; they evolved in various sizes and shapes along the centuries from enclosures of urban gathering places to distributing nodes for masses moving out of monumental public buildings to crossroads for the ever increasing traffic, in concert with the converging pattern of streets.

The post-modern development of urban structure generated a number of urban spaces that are no longer defined by the surrounding architecture of buildings. As Spiro Kostof said "We should accept that the social world of cities that played itself out in the old town square is dying" [3]. The emergence of the consumer society generated new forms of "public spaces": shopping malls and theme parks, atriums and other inner public spaces, strip developments. Pioneered in North America, replicated all over Europe, they made headway in Romania too. The new forms of "privatized public spaces" [3] target consumption and leisure in controlled enclosures. While they enriched the plethora of physical forms, the urban structure burst at its traditional seams, engendering spatial segregation, a new pluralism and eclecticism of urban forms, in a precarious dynamic balance. Giddens defined them as "neutral zones of public indifference" [4] where traditional activities and traditional communities are being replaced by "... a carefully monitored demonstration of what might be called polite estrangement [4].

To answer the question in the title is an ambitious task. The topic is vast and there is an extensive related literature. Our paper will be limited to our recent research. It is empirically grounded yet it is anchored in our broader approach to public space: how to stitch up the urban fabric by integrating new infrastructure with a view to balancing private investment criteria and community interests.

\section{Transformations of the city fabric: a recent history}

Historically Bucharest developed around churches, monasteries and their inns. As gathering points and traditional public spaces, they generated and defined the city's growth through neighbourhoods clustering around them. In the 1930s Haussmanian-type interventions created the layout of a modern city, with large thoroughfares that cut through the historic city center.

One of the major disruption in the city structure occurred in the 1980s. It was then that the authoritarian regime imposed a massive surgery within the traditional urban structure. By extensive demolition of whole neighbourhoods on the right bank of the Dambovitza river a "blank page" was created onto which the visual expression of socialist "grandeur" was projected, i.e. a neoclassical postmodernist thoroughfare, on a scale incongruous with that of the city fabric, fig. 1. The main avenues and the new axis were marked as ceremonial passages by a continuum of high-rise buildings, severing the connections with the preexisting urban structure behind them. This forceful disruption significantly affected the city's capillarity and cohesion, obscuring the clarity of the original distribution of public spaces, some public spaces being obliterated altogether.

No communication or even transition between the two realities have been preserved: the existing urban fabric was brought to a sudden halt by the barrier 
of the new high rises. The only access from the main avenue to the "backyard city" is through passageways, fig. 2 . The loss of urban vernacular repository of the city's history is still being felt as a loss of historical memory.

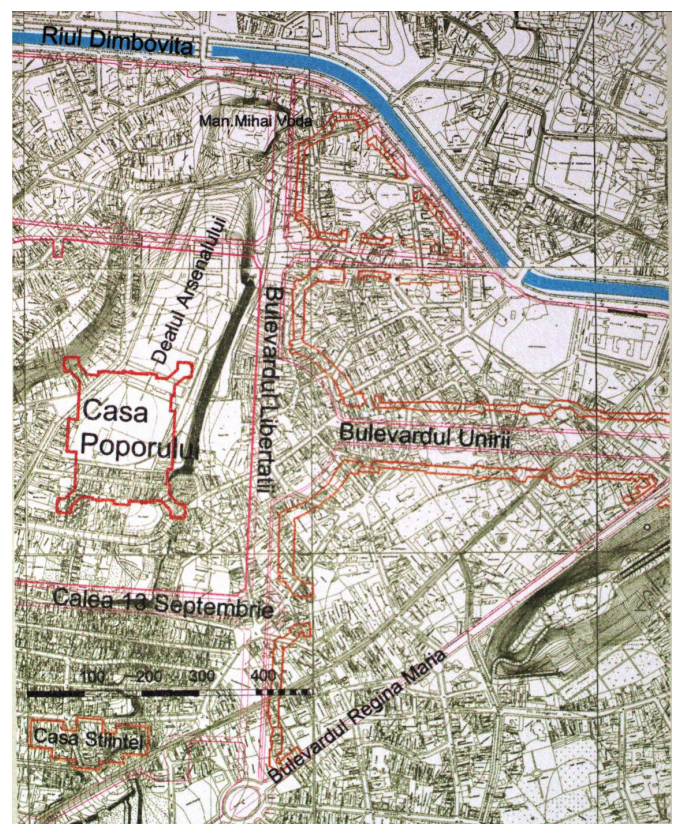

Figure 1: Layout of the former right-bank of the Dambovitza river showing the topography of the Arsenal Hill currently topped by the Palace of the Parliament and the Hill of the Metropolitan Church (courtesy of Andrei Pandele).

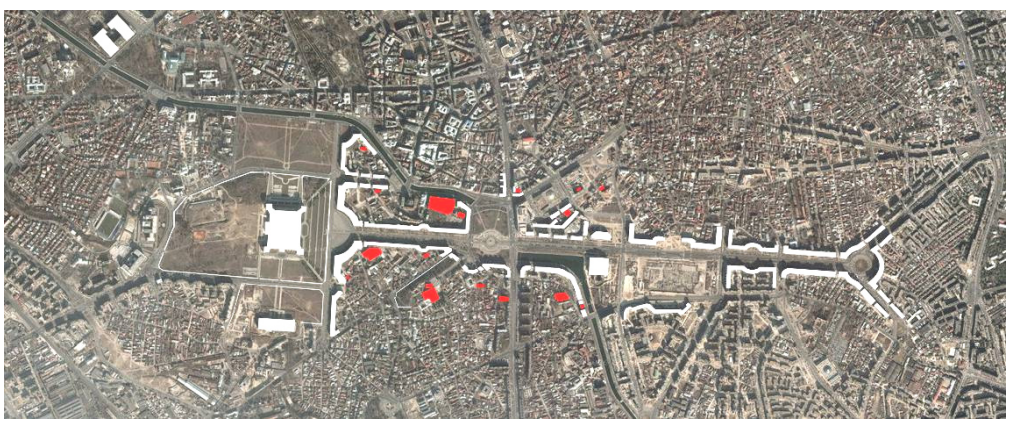

Figure 2: $\quad$ Monumental high-rises created a continuous urban front on both sides of the implanted axis, disrupting the pre-existing urban fabric. 
Other consequences were the creation of vast no-man's lands on the western and southern sides of the Palace of the Parliament, a flat park on its northern side, as well as the whole ensemble turning its back to the river, fig. 3 .

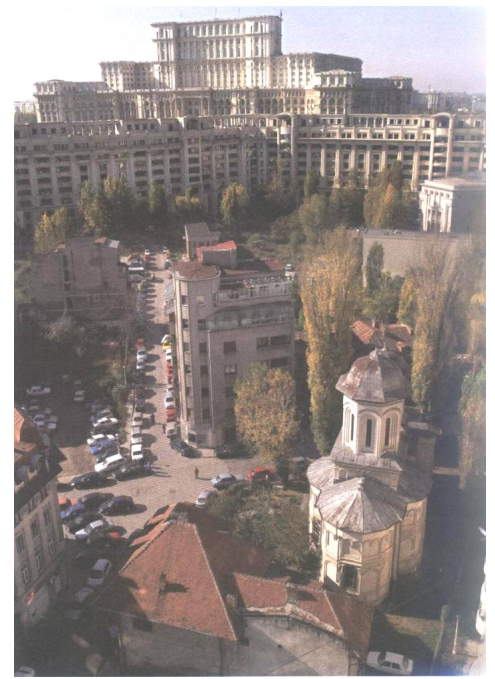

Figure 3: The Palace of the Parliament and the shielding off of the remaining urban tissue (Photograph by Andrei Pandele).

\section{The new context}

Urban structures are context dependent [5]. The political, economic and social changes of the last decade set the context for significant changes in the city's image and structure. Reading of the current urban structure highlights the relationships between the overall economic-social-institutional framework and the changes that occurred. The decline of the major manufacturing industries in the early 1990s freed up some of the former industrial estates providing large areas of usable urban land. This opportunity turned out to be a mixed blessing. On one hand it opened up opportunities to enriching the urban fabric, completing public spaces and inserting new infrastructure; on the other hand it offered temptations to new private interests who failed to balance the relationships between built-up areas and public spaces.

With new types of housing aspirations and housing consumption patterns the urban structure burst at its traditional seems. The early urban sprawl was the outcome of a number of factors; for developers - easily accessible and cheaper land in the sub-urbia; secession drives for a rather limited category of highincome families forsaking the city towards sub-urban residential parks or even gated communities [6]. Built in a speculative manner without the support of services and proper transportation links some of the sub-urban developments became less and less attractive for the new owners. Their major problem remains 
the difficulty to reconnect to the city due to poor transportation infrastructure. With the dramatic increase of cars, traffic within the city and to and from the suburb became a priority.

Re-considering and developing urban public space has recently gained momentum, in an attempt to re-invest urban public space with its complex dimensions and hierarchic structure, accommodating new functions, while coping with the increasing rate of car-ownership.

\section{Building anew within the city's historical fabric}

Planning for the future always had at its core the convergence and distribution of traffic. In an attempt to reconstruct the image of the city and to balance mobility, functionality and livability, an impressive project was launched by the townhall: doubling the North-South axis of Bucharest. The new axis, mapped out on existing streets that are to be enlarged to the double of their original size, aims at diminishing the traffic on the historical North-South axis, whose social-value preservation is considered of higher importance. Buzesti - Uranus thoroughfare would connect the Victoriei Square - where the seat of the Government is located - with the Palace of Parliament; the new axis will therefore connect two squares of political significance.

In order to accomodate the enlargement, extensive demolitions have been carried out on the northern side of the river; urban fabric from the late 1800s was eliminated: mostly two storey-high housing with commercial groundfloor hosting individual manufacturing workshops but also hotels, cinemas and villas.

As all stories go, we have two points of view to consider when taking a closer look at the project. On one hand, the delapidated aspect of the fabric, left largely unattended for by both the municipality and the private owners, was the main argument for carrying out the demolition. Due to flaws in regulation, litigations and conflicting claims of former owners dispossessed during communism, a large number of houses have been taken over by squatters and illicit activities. On another hand, historians raised an alarm call for preserving urban features typical of Bucharest's early urban structure: one of the last two oldest markets of the city is still standing the area, the Matache Market. Up to the mid 1800s, the whole area was all green space - orchards and gardens. With the central railway station built in the vicinity, the area was transformed into a commercial and cultural hotspot. As it catered for train travellers, it became one of Bucharest's main gateway. Although inhabited by low and medium income households, its typology of all-public groundfloors, passageways and inner courtyards, as well as the in-length division and in-depth crossing of the urban fabric offered an undeniable quality for the pedestrian use of public space, fig. 4.

Whether or not the axis project and the subsequent demolitions are justifiable in a global context aiming to reduce private-car traffic has, unfortunately, become irrelevant: it is a fait accompli. What matters most is the issue of how to build anew, in a way that meets economic, social and aesthetical demands of both municipality and the investors, as well as city users. 

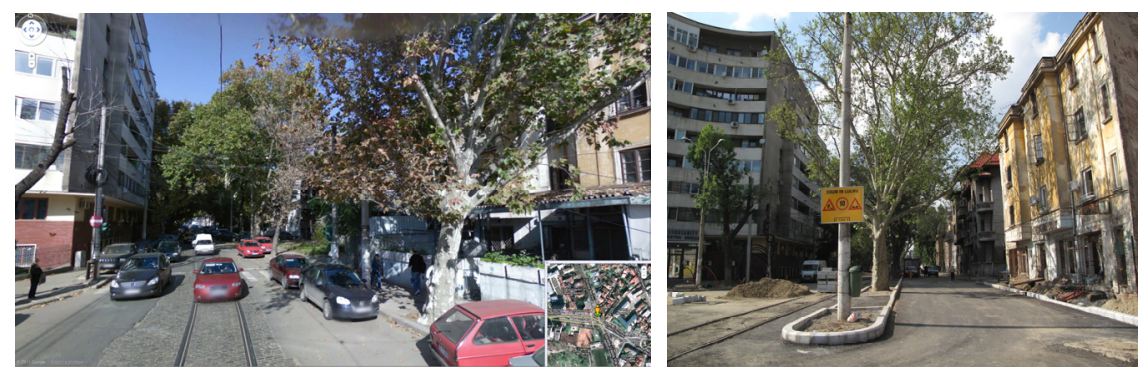

Figure 4: Berzei Street, previous situation: one way road, two wide lanes for car traffic, one tram lane, wide sidewalks allowing front house gardens and terraces. Current situation: two way road, four lanes for car traffic, one tram lane, narrow sidewalks, no front gardens or terraces, no bicycle lanes.
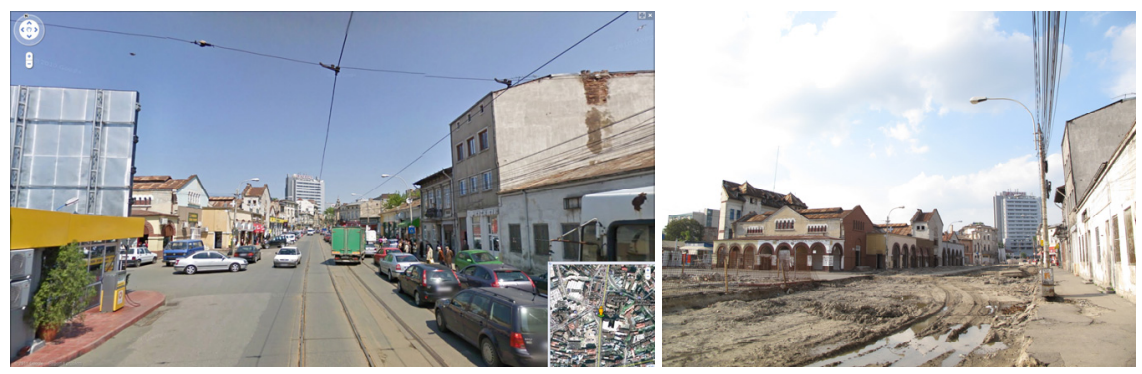

Figure 5: Buzesti Street, Matache Market. Previous situation: two way road, $19 \mathrm{~m}$ wide, two lanes for car traffic, two lanes for tram, commercial groundfloors. Current situation: left side of the road was cleaned for enlargement, the Market may be moved some 20 metres backwards to make way for the $31 \mathrm{~m}$ wide road. Proposed situation: two way road, four car lanes, two tram lanes, $3.5 \mathrm{~m}$ wide sidewalks, two bicycle lanes included.

A framework project was carried out (approved but not yet detailed) under the pressure to provide estimates that would cover costs and turn the project into a profitable investment. The proposed layout would consist of minimum six-storey high slab-like buildings lining the road. Concentration of high density and maximum accessibility along the road is supposed to compensate low density of the existing fabric. No indications have been made as to the functions to be hosted or whether the ground floor would be accessible to the pedestrian public.

In this context, how do we design for urban complexity? How can we achieve a "lively, safe, sustainable and healthy" [7] environment? What have we learned from the failed example of the East-West axis that resulted in the massive urban shielding? How do we fill the voids without leaving residual spaces? How do we stitch-up the new with the existing urban fabric? And, most importantly, which is 
the right answer to all the above questions that could compete with the most profitable yet less sensitive solution?

Jan Gehl's [7] advice is to look, understand and design the city as fit for the eye level: an urban intervention addressing pedestrians, dialoguing with them, inviting them, offering them reasons to come, see, pass through or stop, all of which will become qualities with positive effects on all scales - economic, social, cultural.

Therefore our proposal started from the connection issue: the new road connects North and South but our intervention should allow and encourage sideways crossings into the urban fabric, thus preventing both the "canyon" effect and the resulting shielding. Instead of lining the road, we preserve the former typology of in-depth land division, using a $10 \mathrm{~m}$ wide grid that would match with the scale of the remaining urban fronts.

High-rise slabs as proposed by the town hall offer a continuous front but act as a wall shading the remaining urban fabric, fig. 6 . Moreover, due to their height, they aggressively annul all intimacy for the neighbouring houses.

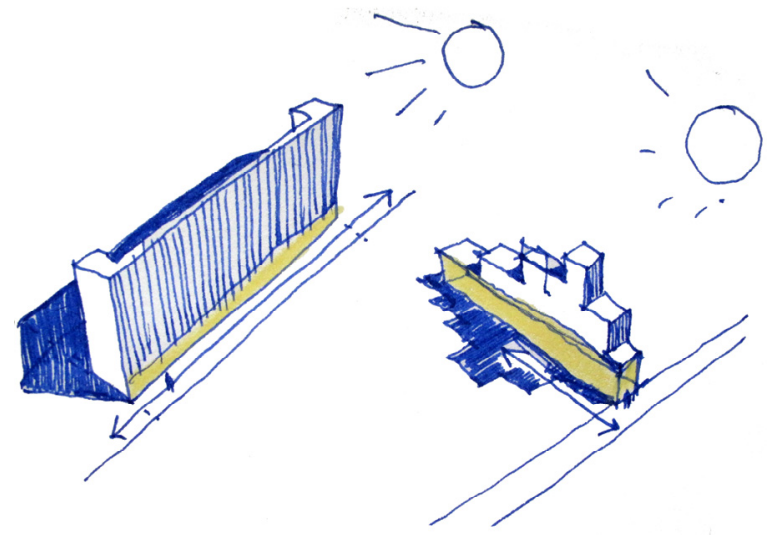

Figure 6: When designing, take sunlight into account.

Our proposal would choose in-depth slabs of varying height, both front and back matching the scale of the existing fabric; while following the rule of successively retreating floors, their height may attain the peak around the slab's mid-length. This way the privacy of the courtyard houses of the existing fabric would not be disturbed. Moreover, we believe that a high density low rise fits better into the context than the low density high rise that the municipality's plan encourages: using up a larger part of the available land but not exceeding the neighbouring heights would compensate the square meters that a high rise may offer, fig. 7.

Turning to the eye level, we propose an all-access commercial and public ground-floor, with a high degree of capillarity: public passageways and inner courtyards connect the new road's sidewalks with the remaining fabric, offering pedestrians several trails for moving around the area: direct connections, 

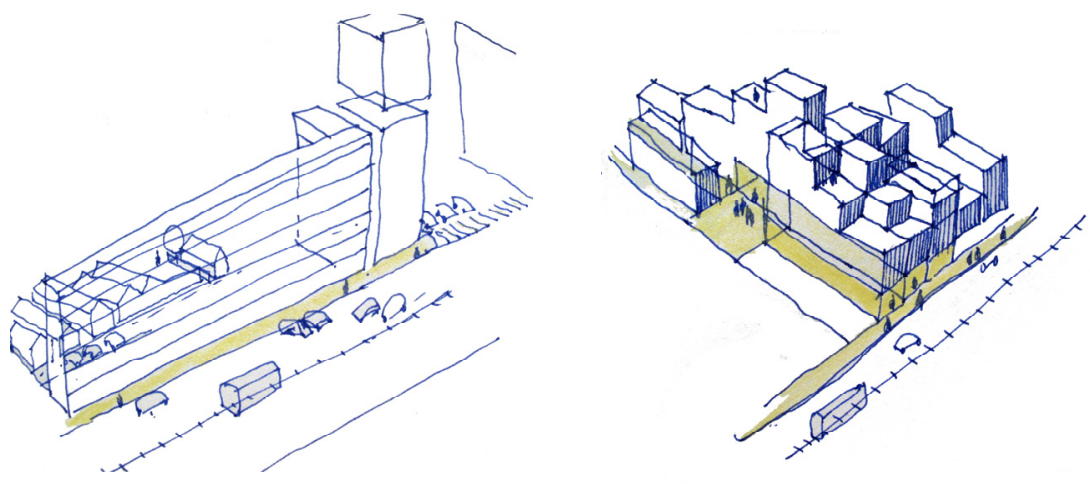

Figure 7: On the left: shielding off the remaining fabric, the in-between space becomes residual. On the right: integrating the urban fabric into the new construction - capillary connections. In yellow: public and commercial space.

shortcuts or longer walking paths, playing areas, sitting areas. The functions on the ground-floor should allow a $24 \mathrm{~h}$ safe access, addressing the time-schedule and the necessities of the residential areas of the remaining fabric, the officeworking personnel and the public coming from other city areas: shops, studios, hairdressers, cafés, restaurants, kindergartens, post-offices, clubs. The upper levels would host offices, banks, brand retail and housing.

A good integration into the existing fabric and typology of the area, a safe and lively environment would benefit not only the neighbourhood, but also the investors, since a larger public would be attracted to the area, fig. 8 and 9 .

As concerns traffic design, we adopt Jan Gehl's strategy [7] of gradually eliminating car traffic lanes and giving back the resulting space to pedestrians, cyclists and public transportation: "let the traffic take care of itself once it has no space to take advantage of". According to studies conducted together with Soren Ene, traffic engineer, eliminating car lanes reduces traffic, narrowing car lanes

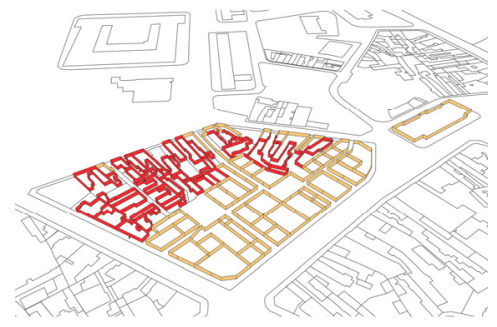

Figure 8: Axonometrical ground floor plan of the proposed ensemble on one specific area, south of Matache Market (in yellow): in red: residential areas (all of which represent the remaining fabric); in yellow - commercial areas. 


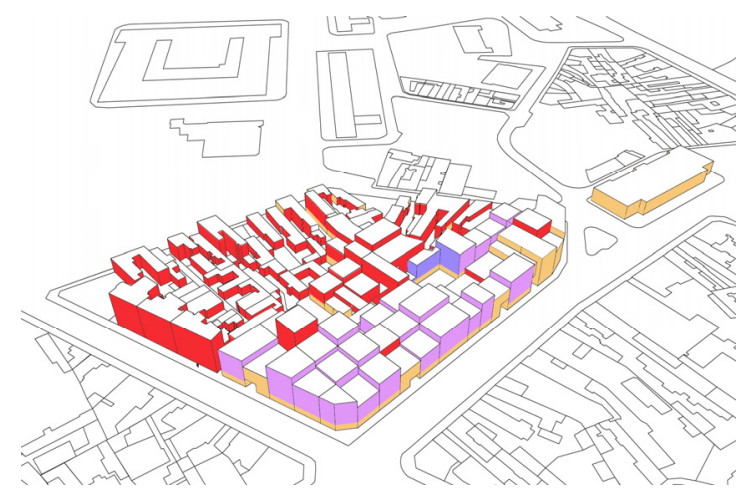

Figure 9: Axonometrical view of the proposed ensemble on one specific area, south of Matache Market (in yellow): in red - residential areas, in yellow - commercial areas, in purple - offices, in blue cultural/community related functions.

reduces speed, eliminating car parking spaces encourages choosing alternative ways of moving around. The impact of developing a $31 \mathrm{~m}$ wide road is very high both on the scale of the area and that of the city: car speed increases, crossing becomes difficult, health risk factors augment, phonic pollution surpasses the norms, fig. 10 and 11.

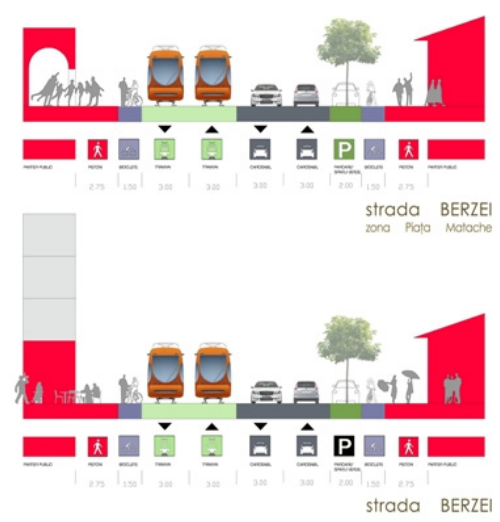

Figure 10: Our proposed street profile: large sidewalks, urban furniture or the buildings themselves offering weather protection to pedestrians, two tram lanes, two car lanes, one parking lane alternating with green spaces, two bicycle lanes. The tram lanes may be used as shared space, increasing thus pedestrian's comfort. 


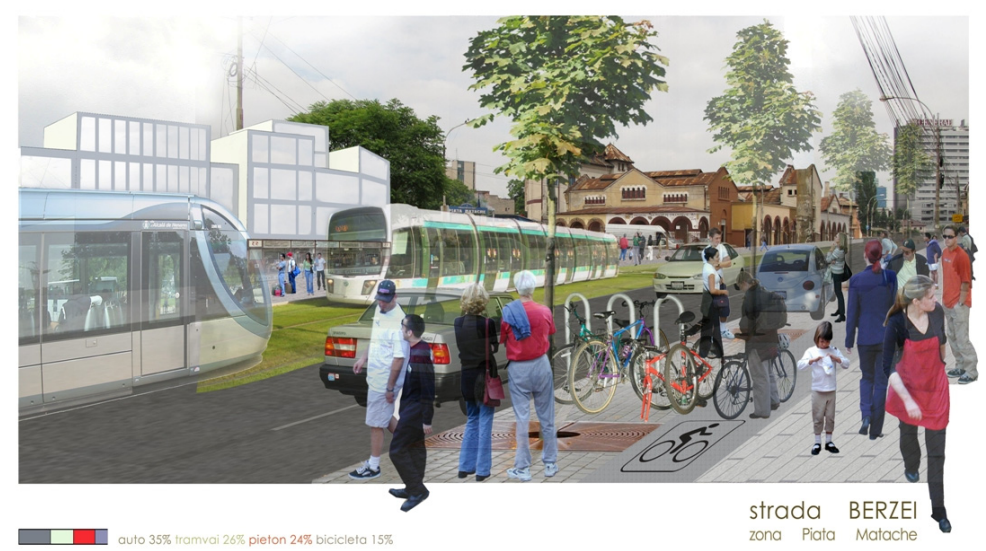

Figure 11: Proposed image of the Matache Market and its environment: proportions are more important than numbers: increasing car traffic lanes and widening the street does not provide more comfortable square meters, but a wise proportional division and allocation of space to functions does.

\section{Conclusion}

The main idea that underpins our research is to look into the long-term consequences of our desinging choices. When the elements of the built environment are no longer seen simply as urban forms, but as areas and sites of connection between social, political and human factors, then important lines of research and inquiry are opened up.

Planning for the future depends on our collective ability of appropriating space. The major aim is to provide a support for decision making in restoring the fundamental role of public urban space in shaping urban form and supporting community life.

\section{References}

[1] Short R., The Urban Order, An Introduction to Cities, Culture and Power, Blackwell, 1996

[2] Kostof S., The City Shaped, Urban Patterns and Meanings Through History, A Bulfinch Press Book, Little, Brown and Company, 1991

[3] Kostof S., The City Assembled, The Elements of Urban Form Through History, A Bulfinch Press Book, Little, Brown and Company, 1992

[4] Giddens, A., The Consequences of Modernity, Cambridge, Polity Press, 1990 
[5] Creanga E., Budisteanu I., Duda M., Sustainable housing for sustainable cities - case study of Bucharest, The Sustainable City VI, Sixth International Conference on Urban Regeneration and Sustainability, WIT UK, University of la Coruna, Spain

[6] I. Budisteanu I., The long-lasting impact of earlier housing policies (pp.221-237) in Housing Finance - New and Old Models, ed. Hegedus J., Struyk, R., Open Society Institute, Budapest, 2005

[7] Gehl J., Cities for People, Island Press, 2010

[8] Radu F., Salembier C., Duda M., Pavelescu T., Proportions, not numbers, Project for the Alternatives for Bucharest Workshop, 2011 